\title{
Teaching Reform and Practice Based on the Progressive Ability Cultivation of Higher Vocational Mechanical Talents
}

\author{
Shukun Gan \\ College of Mechanical and Electrical Engineering, Jilin Institute of Chemical Technology, Jilin \\ 132022, China
}

49141544@qq.com

Keywords: Higher vocational education; Progressive; Ability training; Mechanical basic group

\begin{abstract}
In order to strengthen the training of skilled talents in higher vocational machinery, combined with the OBE engineering education training concept, through the construction of the mechanical basic course group in the training program for high-level mechanical talents, the curriculum is divided into three levels: basic cognition, improvement integration, and practice sublimation. Make the curriculum system step by step, progressively cultivate and improve students' knowledge and ability, and put them into practice. The results show that through the reform practice, the students' comprehensive ability and quality have been effectively improved, and the results have been significantly improved. They have been widely recognized and achieved the goal of cultivating progressive talents. This study has a significant effect on the progressive ability of mechanical talents and can be extended to relevant professional applications, through the reform of the method of higher vocational mechanical basic courses.
\end{abstract}

\section{Introduction}

Higher vocational education mainly cultivates high-skilled applied talents to adapt to social and economic development. Regardless of theoretical basis or practical skills, the teaching should be based on "necessary and sufficient", focusing on practical application [1]. The machinery industry is an important pillar industry of the country. At present, China's machinery industry is developing rapidly, and the market demand for high-skilled talents is increasing [2]. The mechanical basic course is an important carrier for the cultivation of basic professional quality ability of vocational mechanical students. It will have a direct impact on students' learning and mastering follow-up professional courses and graduation work.

\section{Teaching Status of Mechanical Basic Courses}

At present, the basic courses of the mechanical industry in various universities are basically independent of each other. The content of the courses is overlapping and repeated, and the professional relevance is not strong. The setting of the course is out of touch with the actual situation. The teaching process emphasizes theory and light practice, and is separated from the actual job requirements, thus increasing the difficulty of teaching and learning, and affecting the quality of teaching [3]. According to statistics, the establishment of the basic course of mechanical industry in the original talent training program of our school includes more than ten courses. The allocation of time and course content of each course is uneven, the theoretical teaching accounts for more than $80 \%$, and less practical teaching. Teachers are independent, lack communication, the proportion of repeated content of the course is about $20 \%$. Some contents are involved in 3 4 courses. The relationship between the courses is very poor. After the students learn, the knowledge can not be effectively linked to solve the problem comprehensively. The actual problem has seriously affected the teaching effect.

Although the institutes have carried out corresponding research and reforms, the effect is not obvious. The curriculum system cannot meet the requirements of the curriculum content required for the personnel training objectives, nor can it effectively coordinate and link the teaching content between the courses. The application ability cannot be improved, and there is no curriculum system 
suitable for vocational education. Combining the training objectives of our school's mechanical professionals. In the teaching activities, we designed the form of mechanical basic class group, focused on the optimization and integration of learning content, strengthened the connection and inheritance between courses, and the connection of knowledge structure, from shallow to deep, step by step, forming a "progressive" teaching mode. Cultivate students' comprehensive ability, reform teaching methods and means, lay a foundation for the follow-up of professional core courses, and ensure the realization of professional talent training goals. [4,5]

\section{Optimized Integration of Courses}

Principles and Objectives for the Optimization and Integration of the Curriculum. The curriculum system is an important part of the talent training mode. The rational construction of the curriculum system is also an important part of the reform of the talent training mode. Higher vocational education should take the vocational ability training as the foothold and starting point of the curriculum reform [6]. According to the spirit of higher education in the Ministry of Education. Based on the basic principles of "results-oriented, top-level design, scientific and rational, overall planning, division of labor, and integration", the OBE concept is applied and guided by "necessary use". emphasizing application and practicality, optimizing and integrating mechanical basic courses of mechanical engineering, decompose the course tasks and promote the knowledge fusion of each course. A progressive, integrated and coherent curriculum system is formed between the courses [7, $8,9]$.

Mechanical Basic Course Group Progressive Curriculum System Reform. Focusing on the training objectives of the curriculum, combined with the actual education and teaching of our school, the mechanical basic courses of mechanical engineering were integrated. Starting from the top-level design, the group system of "progressive" ability training was constructed, and the whole mechanical basic course was divided into three levels: basic cognition, improvement integration and practice sublimation. The teaching reform and practice are shown in Fig.

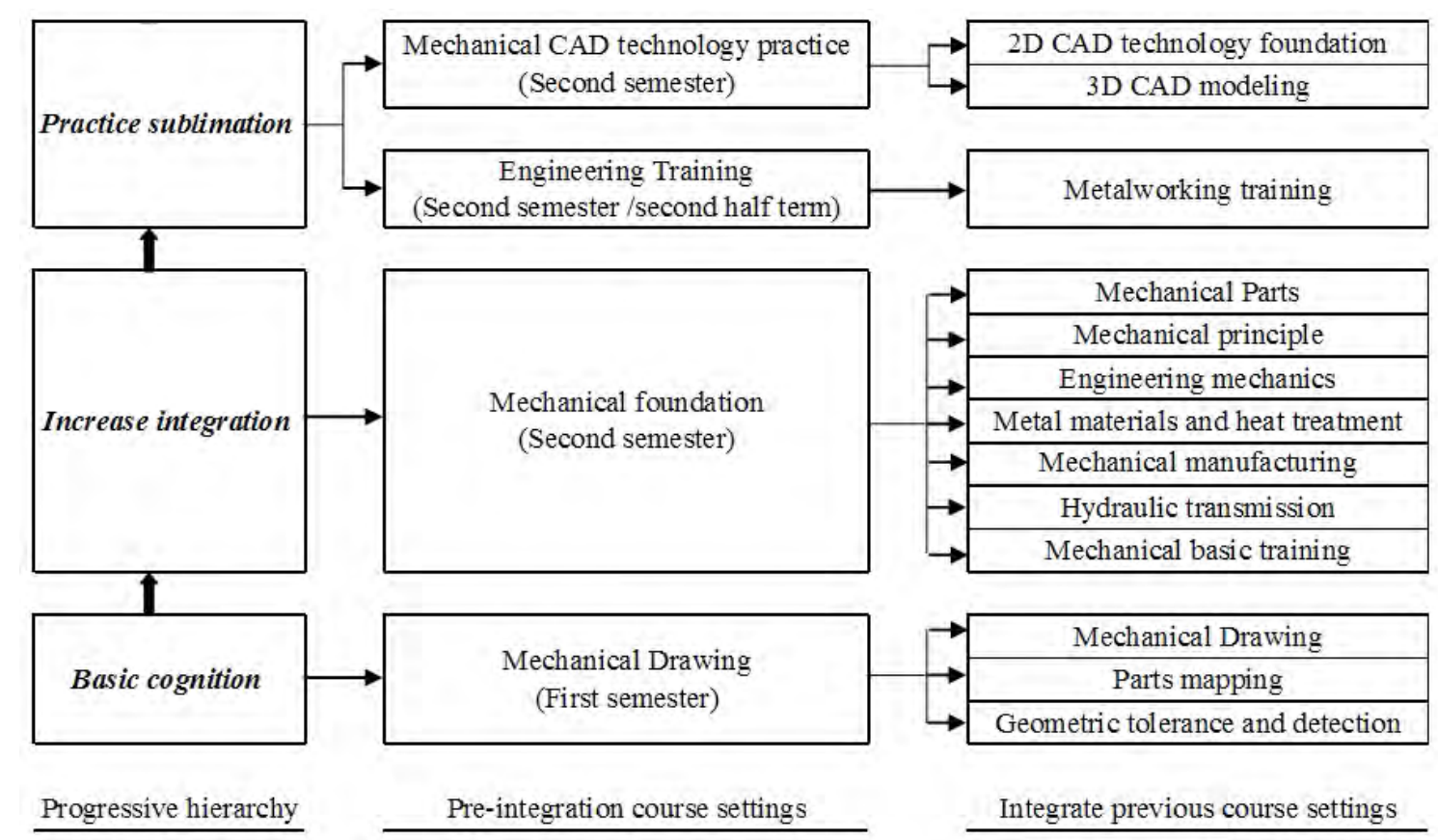

Figure 1. Construction diagram of the progressive mechanical basic group system

Basic Cognition, the integrated Mechanical Drawing course, the conversion of the product and the pattern is carried out, through the reading, modeling and mapping of the product. Carry out 
structural expression, dimensioning, technical requirements, establish and implement national industry standards and normative awareness, cultivate students' professional ability in pattern reading, modeling and mapping, and cultivate professional responsibility such as job responsibility. The Mechanical Drawing course is offered in the first semester. The optimized and integrated course is directly helpful for the further study of the students' mechanical professional courses, and plays an important role in the teaching of mechanical majors [3].

Increase Integration, With the principle of "necessary and sufficient", through learning and optimizing the integrated "Mechanical Foundation" course, students can master the basic theories, basic knowledge, basic methods and skills of machinery. They can analyze the typical mechanical equipment in actual production from a system perspective, and comprehensively apply what they have learned and mastered. Skills solve practical problems in engineering, improve the ability of professional technology application, and correctly solve the practical problems of engineering, and lay a solid foundation for the follow-up of professional courses. The integrated curriculum not only highlights the applicability and practicality, but also strengthens the ability to solve practical problems, and spends more effective time on the training of students' professional skills [3].

Practice Sublimation, Practice is an important means of sublimating the theoretical knowledge of learning. The Mechanical CAD Technology Practice course focuses on cultivating practical hands-on operation ability, strengthening the application ability of students' computer mechanical design software and the learning and understanding of modern design methods and means. After the completion of the Mechanical Drawing course, it will be opened in the second semester and will be opened at the same time as Mechanical Foundation. The Engineering Training course further focuses on strengthening the actual training content of the project, strengthening the organic combination of theoretical teaching and practical teaching, cultivating students' comprehensive application ability of professional basic knowledge, and improving the cultivation of comprehensive application practice ability. The Engineering Training course is offered in the second semester. On the basis of further strengthening the effective improvement, understanding and application of the content and knowledge of the Course of Mechanical Drawing, the knowledge complementarity will be formed and the practice will be sublimated.

\section{Teaching Method Reform}

Through strengthening the construction of professional faculty, through active organization of teaching and research activities, strengthen effective communication between teachers, pay attention to the connection between the teaching content and knowledge level of each course, and improve the curriculum construction .[10] Strengthen the links between the various courses through reform of teaching methods, such as project-based teaching. Applying different knowledge points between the courses through specific questions to enhance the understanding and mastery of knowledge. Improve students' interest in learning by improving the examination, assessment methods, and subject competitions. Based on the talent training goal, pay attention to the setting of each course content in the process of curriculum group construction, and reasonably formulate the curriculum standards and syllabus. Pay attention to the theory and practice, strengthen the cultivation of practical ability, increase the proportion of practice links, and effectively improve students' professional application ability. Make the knowledge system structure reasonable, step by step, and the students' knowledge and ability will be improved progressively.

\section{Teaching Reform Effectiveness}

With the continuous deepening of teaching reform and practice, the structure and level of professional knowledge system in the progressive curriculum system of the mechanical basic course group of our school is more reasonable, forming complementarity and gradual progress, achieving a progressive improvement of students' knowledge and ability training. Through the survey and feedback of our school's mechanical students from recent years, as shown in Table 1, the newly constructed progressive mechanical foundation course group ability training curriculum system is 
fruitful.

Table 1 Teaching reform effectiveness

\begin{tabular}{ccccc}
\hline \multirow{2}{*}{ reform grade } & \multicolumn{2}{c}{ before } & \multicolumn{2}{c}{ after } \\
& 2013 & 2014 & 2015 & 2016 \\
\hline Student course average attendance rate /[\%] & 77.72 & 80.15 & 90.38 & 91.46 \\
Average rate of good results in practice /[\%] & 25.91 & 31.17 & 50.73 & 57.93 \\
Average participation rate in practice /[\%] & 64.77 & 65.52 & 87.46 & 88.41 \\
Student satisfaction rate /[\%] & 75.13 & 73.79 & 88.92 & 89.94 \\
Internship production unit satisfaction rate /[\%] & 72.54 & 71.25 & 90.38 & 91.31 \\
\hline
\end{tabular}

With the principle of "necessary and sufficient", the burden of students' learning is reduced. Each course avoids the repetition and intersection of knowledge, effectively reducing the burden on students. More time and energy will be devoted to the improvement of practical skills, which will increase students' interest in learning and participation.

The proportion of practical teaching links has been strengthened, and the students' hands-on practical ability has been significantly improved. The new system pays attention to the cultivation of professional practice skills, and the comprehensive ability to analyze and solve practical problems in design, processing and manufacturing has been greatly improved.

The awareness of career and responsibility has been strengthened, and the professional quality of students has improved significantly. The course study combines the reality of enterprises and institutions, imparts the latest industry standards and management knowledge, strengthens students' understanding of corporate work, and raises awareness of the importance of execution and teamwork. Students can quickly adapt to their jobs after graduation.

\section{Conclusion}

Through re-optimizing and integrating the mechanical basic courses of mechanical engineering, constructing a more reasonable professional basic course group, strengthening the connection and inheritance between courses, making overall plans, strengthening the foundation, supplementing the gaps, and achieving mutual penetration and intersection of knowledge. Thereby, the curriculum system of talent progressive ability training has been realized, and good results have been achieved.

\section{References}

[1] X.R.Nan,Y.F.Chen and S.W.Pan: Chinese Adult Education(2008)No16,p.130-313. (In Chinese)

[2] J.W.Zhang: Technology Entrepreneur, (2013)No.14,p.192. (In Chinese)

[3] Q.M.He,L.S.He: Vocational and Technical Education, (2010)No.17,p.17-19. (In Chinese)

[4] B.Tang,G.Z.Jiang,Y.Hou,G.M.Zou,X.D.Wang and G.F.Li: College Education, (2006)No.04,p. 130-132. (In Chinese)

[5]X.Wu: Chinese University Teaching,(2017)No.02,p. 78-83. (In Chinese)

[6]Y.Huang,L.M.Qiu: Vocational and Technical Education,(2008)No.08,p.29-30. (In Chinese)

[7] Z.Li: Chinese University Teaching,(2012)No.03,p. 12-14+56. (In Chinese)

[8] Z.Li: Chinese University Teaching, (2012)No.03,p12-14+56. (In Chinese)

[9] H.S.Xiao,H.S.Chen and L.Chen: Human Resource Management, (2014)No.01,p.147-148. (In Chinese)

[10]X.X.Zou: Research on the Construction of Innovative Talent Team in Innovative Cities(MS., Hefei University of Technology,China 2013),p.25. 